\title{
Correspondência e não correspondência prosódicas em aberturas de conversas telefônicas no português europeu
}

\author{
Ayane Nazarela S. de Almeida \\ Doutoranda em Linguística. Programa de Pós- \\ graduação em Letras e Linguística, Universidade \\ Federal de Alagoas, Brasil. \\ ayanesantos@hotmail.com
}

René Alain Santana de Almeida Doutorando em Linguística. Programa de Pósgraduação em Letras e Linguística, Universidade Federal de Alagoas, Brasil.

renealain@hotmail.com

Resumo: Este artigo objetiva analisar a correspondência e a não correspondência prosódica entre pares adjacentes nas sequências de abertura em interações conversacionais ao telefone no português europeu. Um corpus de 52 gravações telefônicas foi utilizado para este fim. O parâmetro prosódico selecionado para a análise foi o contorno entoacional.Os resultados indicam que a correspondência prosódica é um fenômeno produtivo em sequências de abertura de conversas telefônicas no português europeu, estando em geral associadaà demonstração de colaboração para o desenvolvimento da conversa.

Palavras-chave: Correspondência prosódica; sequência de abertura; conversas telefônicas

\section{OYedeJI MUSILIYU}

Doutorando em Linguística. Programa de Pósgraduação em Letras e Linguística, Universidade Federal de Alagoas, Brasil. bodeses@yahoo.fr

\section{Miguel Oliveira JR.}

Doutor em Linguística. Faculdade de Letras, Universidade Federal de Alagoas, Brasil. miguel@fale.ufal.br

Abstract: This paper aims at analyzing the acoustic phenomena known as prosodic matching and prosodic non-matching in European Portuguese telephone opening sequences. A corpus consisting of 52 different telephone conversation recordings was used to this end. The prosodic parameter that was selected for the analysis was pitch contour. The results indicate that prosodic matching is a robust phenomenon in European Portuguese telephone opening sequences, being generally associated with the demonstration of collaboration for the development of the conversation.

Key-words: Prosodic matching;opening sequence; telephone conversation 



\section{Introdução}

Um dos enfoques na área de análise da conversação tem sidoa análise decomo se organizam as interações mediadas por telefone. Estudos como os de Schegloff (1968), Freitas (2010), Arminen e Leinonen (2006) já exploraram a estrutura conversacional ao telefone, sob diferentes perspectivas, em diferentes línguas.

Ao analisar um vasto corpus de conversas ao telefone em inglês norte-americano, Schegloff (1968) observou uma estrutura básica recorrente que, segundo ele, apresenta a seguintes seções: (i) chamada-resposta, (ii) identificação e reconhecimento, (iii) troca de cumprimentos e (iv) "como vai?"; em seguida, avançase para o conteúdo da conversa. De acordo com Freitas (2010), a estrutura da abertura conversacional em português europeu (PE) ao telefone fixo ${ }^{1}$ se assemelha àquela verificada por Schegloff (1968).

Freitas (2010) propõe que as estruturas conversacionais ao telefone são constituídas de pares adjacentes, o primeiro par adjacente (PPP) e o segundo par adjacente (SPP), constatando que o primeiro turno da conversa é, simultaneamente, a primeira e a segunda parte de um par. Por exemplo, em "resposta ao toque do telefone", o telefonado diz "estou". Esse primeiro turno produzido por ele não apenas responde ao toque como apela para que o interlocutor fale.

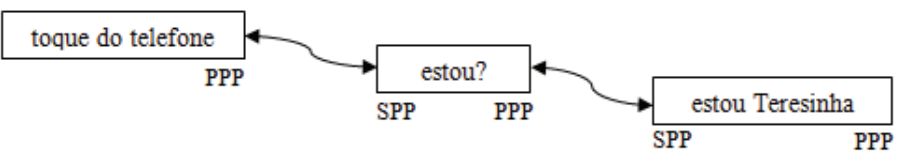

Fig. 1: Esquema ilustrativo de estrutura conversacional ao telefone em pares adjacentes Fonte: FREITAS (2010)

Pesquisas prévias já observaram o importante papel que a prosódia tem na estruturação de conversas

\author{
${ }^{1}$ Os estudos de Schegloff \\ foram todos baseados em \\ conversas ao telefone \\ fixo. A estrutura da \\ abertura conversacional \\ em telefones móveis (e \\ mesmo em telefones \\ com identificador \\ de chamada) pode \\ variar (HUTCHBY \\ \& BARNETT, \\ 2005; ARMINEN \& \\ LEINONEN, 2006). \\ Todas as considerações \\ aqui feitas referem-se \\ a conversas ao telefone \\ fixo.
}


telefônicas. Dentre os quais, destacamos Reed (2012) que analisou o fenômeno da orientação prosódica através de um estudo sobre a colaboração prosódica de participantes durante a interação conversacional ao telefone. Entretanto, ainda são poucos os estudos de parâmetros prosódicos envolvidos nesse tipo de interação.

Reed (2012) destaca que o termo "orientação" tem sido usado em estudos de análises conversacionais para descrever diversas formas de reações que podem ser observadas entre os interlocutores. Para a autora, a orientação prosódica descreve o processo em que um falante responde prosodicamente à prosódia do outro falante no turno imediatamente posterior, demonstrando se está colaborando ou não para o desenvolvimento da conversa.

A orientação prosódica se realiza através de quatro diferentes procedimentos: correspondência prosódica, não correspondência prosódica, continuação prosódica e complementação prosódica. A correspondência prosódica, foco do presente estudo, é entendida por Reed (2001) como a reprodução de parâmetros prosódicos de falantes pelos seus interlocutores, tais como: contorno entoacional, intensidade e velocidade de fala. A autora salienta ainda que entre esses parâmetros, o contorno entoacional é o que melhor expressa ocorrências mais frequentes de correspondência prosódica.

Este estudo objetiva analisar a correspondência e a não correspondência prosódicas entre pares adjacentes nas sequências de abertura em interação conversacional ao telefone fixo, no português europeu, partindo da hipótese de queno caso de haver uma correspondência prosódica entre os interlocutores, pressupomos, seguindo a literatura, que há entre as partes colaboração para a continuidade da conversa. A não correspondência prosódica, por sua vez, cumprirá funções conversacionais diametralmente opostas da correspondência prosódica, 
indicando desinteresse em colaborar com o desenvolvimento da conversa em curso. Como, todavia, e seguindo a hipótese lançada, o alinhamento conversacional colaborativo é normalmente esperado em práticas conversacionais, espera-se que a correspondência prosódica seja um fenômeno mais produtivo em sequências de abertura de conversas ao telefone no PE que a não correspondência prosódica.

\section{Sequência de abertura conversacional ao telefone}

As investigações de Schegloff (1968) sobre a abertura das conversações telefônicas em inglês norteamericano têm sido consideradas como motivadoras de diversos outros estudos,tais como: Reed (2012), para o inglês britânico; Reiter e Luke (2010), para o cantonês, espanhol da América Latina, grego, sueco, holandês e inglês, Grieve e Seebus (2008), para o inglês australiano e para o alemão;Arminen e Leinonen (2006), para o finlandês; Park (2002), para o japonês e o coreano; Sifianou (2002), para o grego.A não ser por alguns exemplos isolados, como o de Freitas (2010), não há estudos sistemáticos das características da conversação telefônica para o português europeu.

De uma maneira geral, o que se tem observado é que os participantes de uma conversação típicade telefone tendem a seguir uma sequência na iniciação da conversa, apresentadoelementos pré-conversacionais, tais como resposta à chamada, identificação e demonstração de reconhecimento, seguidos da troca de cumprimentos e da sequência “como-vai?". Avançam, a partir deste ponto, para o conteúdo da conversa, propriamente.

Contudo, a depender da cultura dos falantes envolvidos na interação, a apresentação desses elementos pré-conversacionaispode variar. Por exemplo, a estrutura 
conversacional ao telefone em finlandês, de acordo com ArmineneLeinonen (2006)é diferente da do inglês, por apresentar, via de regra, uma abertura com autoidentificação como resposta à ligação.Em outras palavras; o telefone toca e os participantes imediatamente se identificam, não havendo a etapa da chamada-resposta identificada, tal como ocorre no inglês e no português europeu,por exemplo.Portanto, as autoras apresentam a seguinte sequência de abertura em telefones no finlandês: a identificação ea saudação.

Freitas (2010), em sua análise sobre a forma não-marcada de sequências de abertura ao telefone no português europeu, contesta o que Schegloff define, a seu ver de forma redutora, como "resposta ao toque do telefone" demonstrando que ao iniciar uma conversa ao telefone, o telefonado diz "estou?". Logo, esse primeiro turno produzido por ele não apenas responde ao toque como apela para que o interlocutor fale. Então o telefonante replica com outro "estou",e o telefonado ao enunciar o seu segundo "estou", indica canal aberto para continuidade da comunicação.

Observa-se, portanto, que, em português europeu, a sequência de iniciação é realizada normalmente através de um par de formas do verbo "estar". De acordo com Freitas (2010), o PPP do verbo "estar" normalmente apresenta um tom ascendente, típico de questionamentos, enquanto que o SPP tem um tom descendente, típico de assertivas.Além de caracterizar esses pares adjacentes nas sequências de abertura de conversas telefônicas em $\mathrm{PE}$, a entoação parece cumprir outra função, conforme abordamos a seguir.

\section{Correspondência prosódica}

$\mathrm{Na}$ organização da sequência conversacional, cada vez que ocorre uma transição de turno, os 
participantes têm a opção de continuar a trajetória de ação (tópico) previamente estabelecida ou iniciar um novo tópico conversacional. Pesquisas como as de Local (1992) e Couper-Kuhlen (2004) abordam o papel da prosódia para a organização de sequência e sugerem que a continuação de um padrão prosódico anterior indica continuação da sequência, enquanto que a ruptura com os padrões prosódicos anteriores está associada ao início de um novo tópico.

De acordo com Reed (2012), a prática da orientação prosódica, relação prosódica e sequencial entre os turnos anterior e seguinte, é considerada como uma prática fonológica primária para a organização sequencial. A orientação prosódica refere-se à maneira pela qual os falantes orientam prosodicamentesuas ações, baseando-se na prosódia utilizada pelo falante anterior, seja para dar continuidade a um tópico ou para iniciar outro. Trata-se, portanto, de uma estratégia de discurso local que serve para indicar a negociação de continuidade tópica e, muitas vezes, não dura mais do que duas correspondências de turnos.

Uma das formas de orientação prosódica, conforme já mencionamos, é acorrespondência prosódica, prática que consiste na repetição de um ou mais recursos prosódicos utilizados pelo falante imediatamente anterior.Quando, por outro lado, turnos seguintes são produzidos com uma prosódia diferente da utilizada no turno anterior, observa-se, neste caso, aquilo a queReed (2006) se refere como nãocorrespondência prosódica.

Há ainda, de acordo com a autora,outras formas de orientação prosódica: a complementação prosódica, em que certos tipos de contornos entoacionais tornam os próximos previsíveis ao falante seguinte; e a continuação prosódica, que ocorre frequentemente em sequências de turnos colaborativos, ou seja, quando um turno é iniciado por um falante e outro falante continua se apropriando 
do padrão prosódico exatamente onde o falante anterior parou.Todas essas manifestações de orientação prosódica estão presentes ao longo de conversas ao telefone, entretanto, a mais frequente delas em sequências de abertura parece ser a correspondência prosódica(REED, 2001), razão pela qual foi a forma selecionada para a análise no presente estudo.

Pesquisas prévias descreveram usosespecíficos de correspondência prosódica em interação linguística. Couper-Kuhlen (1996), por exemplo, investigou a correspondência prosódica de pitchregister em chamadas de um programa de rádio, verificando que os participantes apresentaram similaridade de tom, ou seja, uma concordância prosódica relativanos contextos de citação; já emcontextos de imitação, observou que os participantes demonstraram o mesmo tom,uma concordância prosódica absoluta.

Em um estudo realizado em interações conversacionais em sala de aula, Reed (2010) mostra que a correspondência prosódica e padrões prosódicos específicos são interpretados como indícios de emoções positivas e de contribuições para o sucesso interacional entre professor e aluno.

O que esses estudos sugerem é que a prática da correspondência prosódica indica que os participantes estão continuamente conscientes das escolhas prosódicas dos coparticipantes. Para além disso, propõem que em alguns momentos da conversa é importante explicitar, enquanto participante da interação conversacional - e para que ela se desenvolva adequadamente -, a percepção dessa escolha prosódica, mediante a reprodução ou não do padrão prosódico utilizado pelo interlocutor.

O objetivo aqui, como já anunciado, é examinar o fenômeno da orientação prosódica, mais especificamente da correspondência prosódica, em interações 
conversacionais ao telefone no português europeu. Para isso, examinaremos um dos parâmetros prosódicos, o contorno entoacional; escolha justificada pelo fato de quea literatura tem indicado que a mais frequente ocorrência decorrespondência prosódicatem sido o matching do contorno entoacional (REED, 2012).

O contorno entoacionalrepresenta um movimento melódico de pitch que pode ser ouvido como um todo coerente, tipicamente transcrito como uma unidade entoacional. ${ }^{2}$ Desse modo, após a produção de um contorno, o falante seguinte pode repetir esse mesmo contorno no seu próprio turno.Quando isso ocorre, está estabelecido um matching (REED, 2001).

\section{Metodologia}

O materialde análise desta pesquisa consiste emexcertos provenientes de um corpus de 52 conversas telefônicas elaborado pelo Centro de Linguística da Universidade de Lisboa. As conversas em causa foram digitalmente gravadas pela Portugal Telecom, em formato WAV não-comprimido, com separação de canais. Todos as chamadas registadas foram feitas a partir de telefones de rede fixa em novembro de 2001. Trata-se de conversas entre familiares e amigos ou colegas, razão pela qual o grau de informalidade é sempre elevado. Além disso, o fato de grande parte dos participantes não saberem que estavam a ser gravados no momento confere a estes dados uma espontaneidade sem precedentes.

O quadro teórico adotado para examinar a correspondência / não correspondência prosódica no corpus é o da análise da conversação (AC).As análises acústicas foram realizadas através do aplicativo computacional Praat. Num primeiro momento, os fragmentos correspondentes às sequências de abertura das conversas foram segmentados em unidades entoacionais.Em seguida, esses fragmentos

\footnotetext{
${ }^{2}$ Segmento funcional básico do discurso, definido principalmente em termos de contornos entoacionais coesivos, delimitados por elementos prosódicos diversos, isolados ou em conjunto, tais como pausas, mudanças na F0, na duração, na intensidade e na qualidade de voz (CHAFE, 1994).
} 
foram analisados de maneira semi-automática mediante a utilização do script Prosody Pro (XU, 2012).

O Prosody Pro coleta informações de F0 em trechos pré-selecionados no Praat. Para cada trecho, o script coleta valores de F0 em intervalos de tempo equidistantes. A quantidade de vezes que o script coleta essa informação é predefinida pelo usuário. A vantagem do uso deste script para a análise que aqui se propõe repousa no fato de que, ao usar pontos alvos distribuídos equidistantemente, é possível comparar de maneira mais adequada contornos prosódicos de unidades entoacionais de diferentes tamanhos.

A partirdos dados de F0, estilizados com base nas informações de vinte pontos alvos coletados pelo Prosody Pro, elaboramos um gráfico representativo dos pares adjacentes nas sequências de abertura analisadas e verificamos, visualmente, as similaridades e dissimilaridades entre os contornos apresentados.

A Fig. 2 abaixo ilustra um caso de correspondência prosódica entre um par adjacente (olá / olá)na sequência de abertura de uma das conversas telefônicas de nosso corpus.

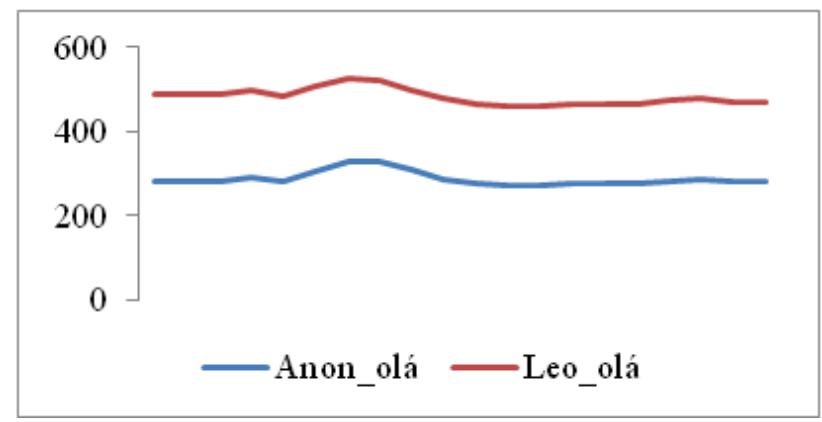

Fig. 2: Contornos estilizados de F0 (C45)

A Fig. 2 evidencia que a estilização dos contornos entoacionais,feita a partir do Prosody Pro, oferece uma melhor visualização para verificar possíveis semelhanças entre esses contornos. 


\section{Análise dos dados}

Do corpus analisado, apenas 4 das 52 gravações telefônicas não apresentaram nenhum par adjacente na sequência de abertura e, portanto,foram desconsideradas. Constatamos que grande parte dos pares adjacentes nas sequências de abertura das conversas telefônicas em nosso corpus apresenta correspondência prosódica, o que geralmente indica colaboração entre as partes na continuidade da conversa (REED, 2012). Em seguida, ilustramos exemplos, do corpus analisado, de presença e ausência de correspondência prosódica.

\subsection{Correspondência prosódica}

A seguir, apresentamos algunsexemplos de correspondência prosódica em sequências de abertura extraídas de nosso corpus que indicam colaboração dos interlocutores em continuar a conversa.

O exemplo abaixo ilustra uma típica sequência de abertura nas conversas telefônicas em nosso corpus. Como as figuras 3, 4 e 5 logo a seguir salientam, praticamente todos os pares adjacentes nessa sequência de abertura possuem o mesmo contorno entoacional, o que evidenciam a robustez deste fenômeno nos elementos pré-conversacionais em diálogos ao telefone.

\section{C50}

0 (toque do telefone)

1 VITOR: estou //

2 RAQUEL: estou / Vítor //

3 VITOR: sou //

4 RAQUEL: olá / tudo<bem>? //

5 VITOR: <estás $>$ boa? // tudo < bem $>$ // 


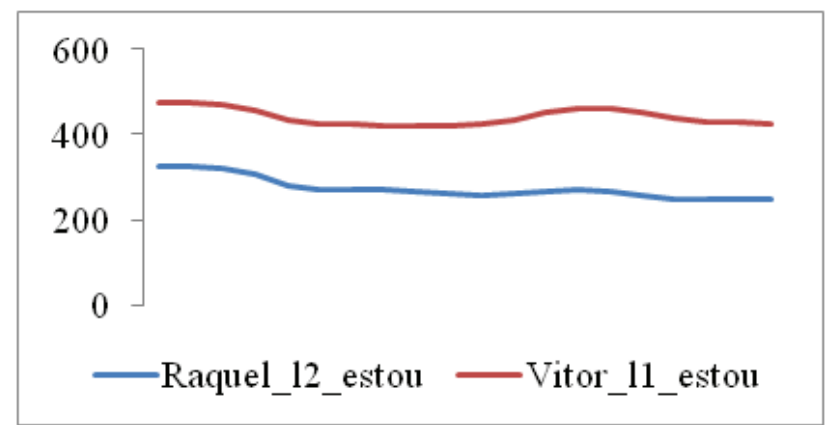

Fig. 3: Contornos de F0 (C50: estou / estou)

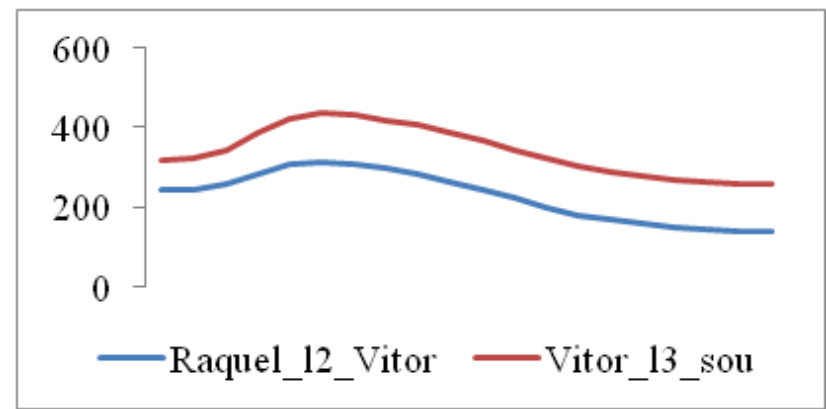

Fig.4: contorno de F0 (C50: Vitor / sou)

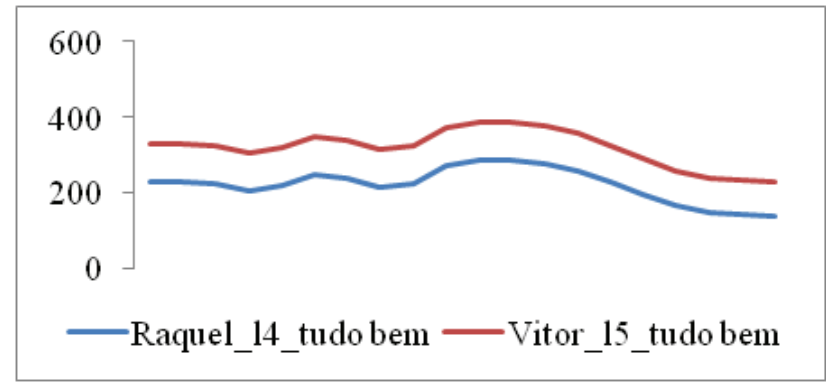

Fig. 5: Contornos de F0 (C50: tudo bem/tudo bem)

Ilustramos outros exemplos do nosso corpus em que ocorre correspondência prosódica entre pares adjacentes nas sequências de abertura da conversação telefônica.Observamos as semelhanças entre os contornos entoacionais nas figuras 6, 7, 8 e 9. 


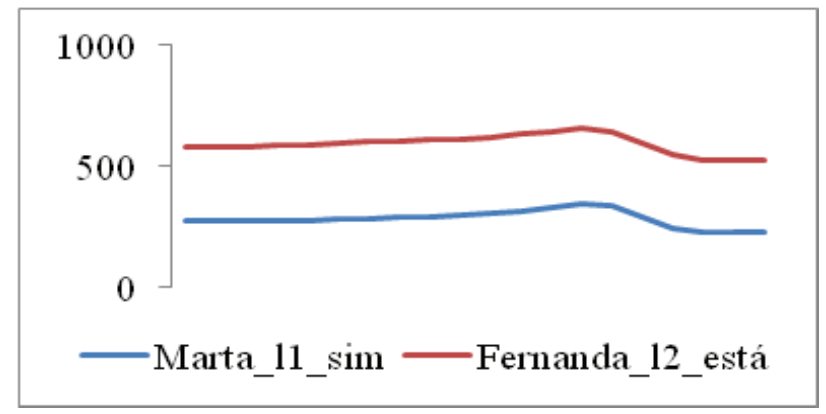

Fig. 6: Contornos de F0 (C32: sim/ está)

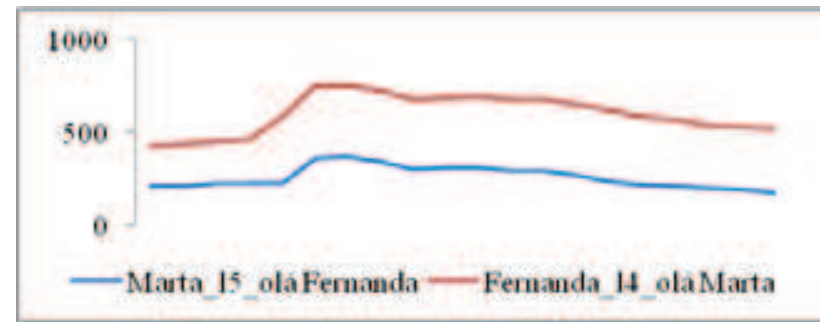

Fig. 7: Contornos de F0 (C32: olá Marta / olá Fernanda)

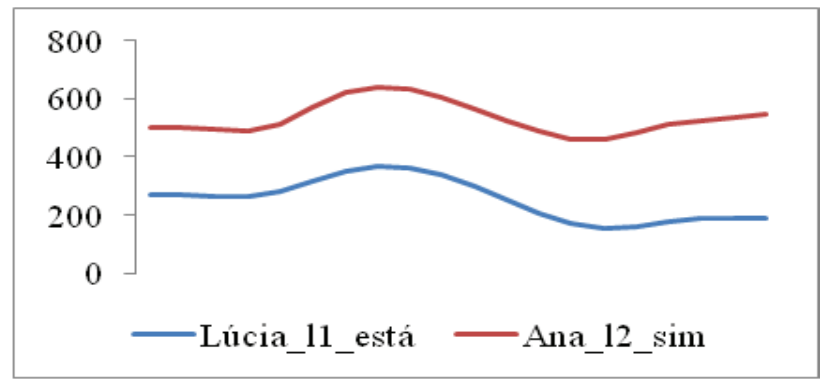

Fig. 8: Contornos de F0 (C38: está /sim)

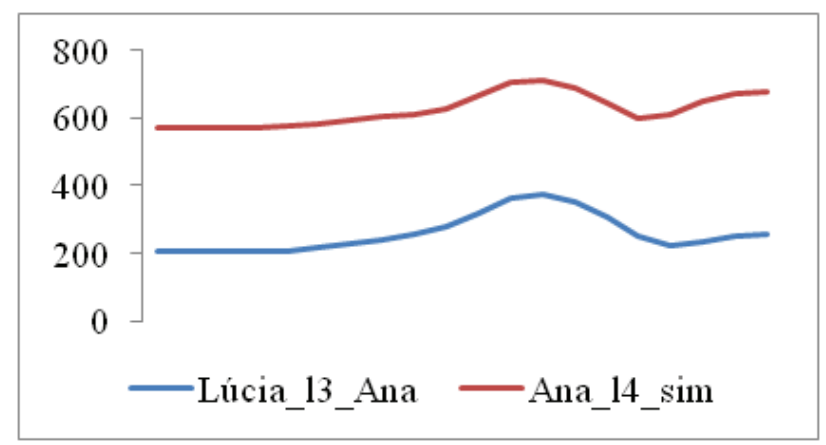

Fig. 9: Contornos de F0 (C38: Ana/ sim) 
As semelhanças entre os contornos entoacionais evidenciam correspondência prosódica e indicam colaboração entre os interlocutores para a continuidade da conversa.

É importante observar que a correspondência prosódica pode estar associada a outras funções, além da indicação de colaboração entre as partes em um diálogo. Essas funções estão relacionadas às características da conversa em que o procedimento é empregado. Na fala ao telefone, a correspondência prosódica pode cumprir funções específicas a este tipo de interação.

Em alguns casos, por exemplo, a correspondência prosódicaestá associada a uma indicação deincerteza, por parte de um dos interactantes,da identidade de seu interlocutor. Nessas circunstâncias, a tentativa de aproximação da prosódia do outro falante pode ser interpretada como uma estratégia utilizada pelo interactante que não reconhece a voz de seu interlocutor para adiar a sequência de identificação,e assim ganhar tempo para reconhecer a voz do outro lado da linha, sem ameaçar a sua face positiva (BROWN \& LEVINSON, 1987), o que fatalmente aconteceria se explicitasse o não reconhecimento de seu interlocutor. O exemplo abaixo ilustra essa situação:

C01

0 (toque do telefone)

1 LUISA: está //

2 MATILDE: estousim //

3 LUISA: eh / está / muito bom dia //

4 MATILDE: bomdia //

Neste caso, os interlocutores parecem não reconhecer com quem estão falando e tentam prolongar a sequência de abertura para a identificação, utilizando a correspondência prosódica, conforme os contornosentoacionaisestilizados (Fig. 10 e 11 abaixo) 
comprovam. Aqui, a correspondência prosódica é utilizada não apenas para indicar colaboração para a continuidade da conversa, mas também como um procedimento de atenuação deum ato ameaçador à facedos interactantes, especificamente, e de acordo com a proposta de Brown eLevinson (1987), uma estratégiade polidez positiva ${ }^{3}$.

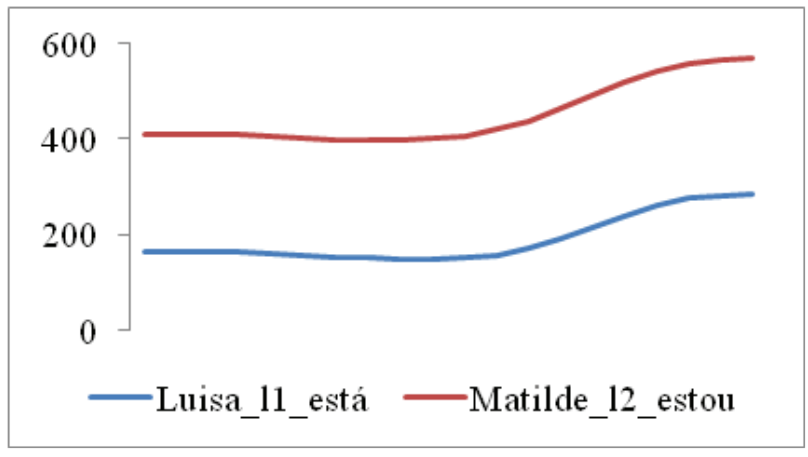

Fig.10: Contornos de F0 (C01: está / estou)

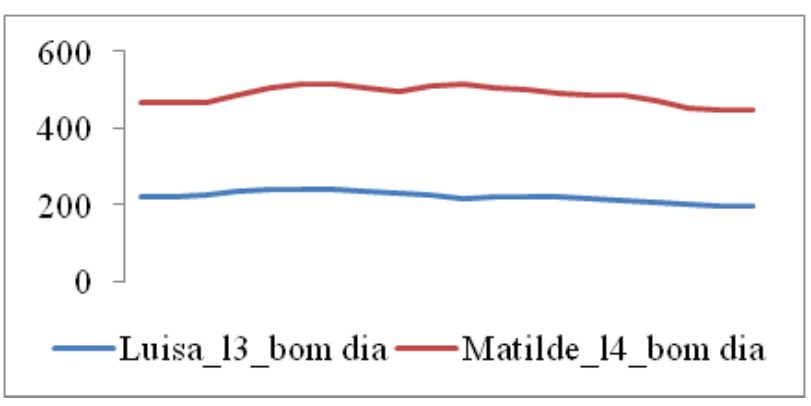

Fig. 11: Contornos de F0 (C01: bom dia / bom dia)

\subsection{Não correspondência prosódica}

São poucos os casos de não correspondência prosódia em nosso corpus, como já reportado. Se a correspondência prosódica indica colaboração para continuidade da conversa, a não correspondência prosódica indicará exatamente o oposto. Trata-se, portanto, de um caso marcado. Merece, a despeito disso - ou, por outra, precisamente por este motivo-, atenção.
3 A polidez positiva é o desagravo à face positiva do interlocutor. Consiste em satisfazer, parcialmente, as aspirações desse interlocutor, dando a entender que há desejos comuns entre ambos (BROWN e LEVINSON, 1987). 
Oexemplo a seguir ilustra um caso de não correspondência prosódica no corpus. No exemplo, LUIS é o telefonado:

\section{C09}

0 (toque do telefone)

1 LUIS: está //

2 LUISA: está / olá //

3 LUIS: olá //

4 LUISA: estásbom? //

5 LUIS: [NOVO TÓPICO] diz //

6 LUISA: então? / estás com a pressa? //

O primeiro par adjacente (está / está) apresenta correspondência prosódica, seguindo o padrão da maioria das conversas do corpus (Fig. 12 abaixo):

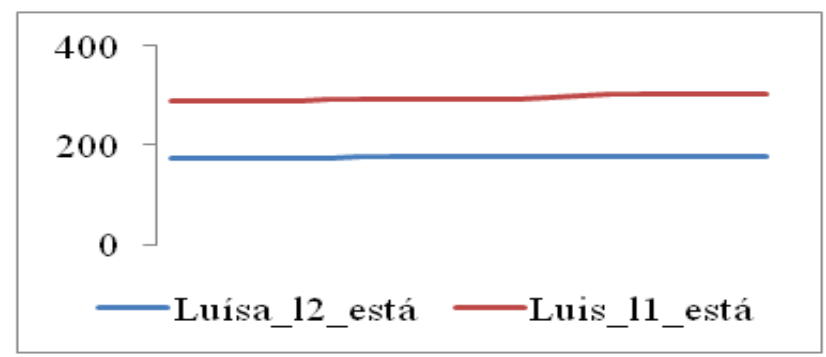

Fig. 12: Contornos de F0 (C09: está / está)

O segundo par adjacente, no entanto, não apresenta correspondência prosódica, no que respeita ao contorno entoacional:

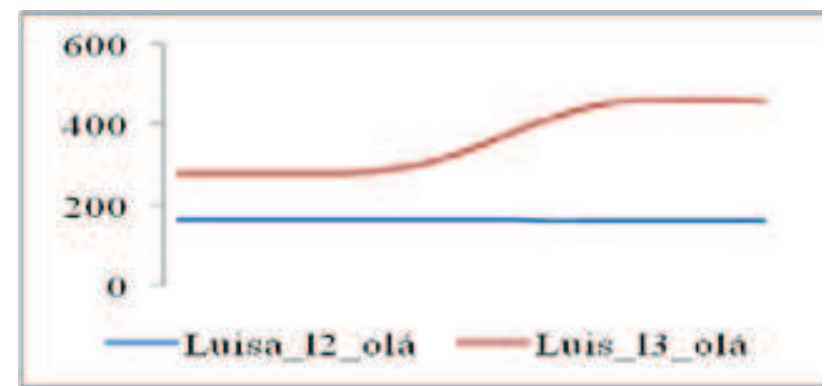

Fig. 13: contorno de F0 (C09: olá / olá) 
A não correspondência prosódica pode ser interpretada como uma indicação de que o telefonado (LUIS)reconheceu a interlocutora (LUISA), mas não tem interesse em colaborar para a continuidade da conversa. Essa falta de interesse é confirmada no par adjacente seguinte, quando Luísa pergunta "estás bom?" e ele não responde, apenas replica com um verbo no imperativo afirmativo: "diz", o que é considerado inapropriado pela interlocutora, que interpela: “então? / estás com a pressa? //".Aprimeira indicação de não colaboração para a continuidade da conversa, portanto,foi feita, neste caso, mediante o emprego da não correspondência prosódica.

Assim como acontece com a correspondência prosódica, a não correspondência prosódica pode estar também associada a outras funções conversacionais. Os primeiros pares adjacentes do exemplo a seguir apresentam correspondência prosódica, conforme demonstram as Fig.14 e 15. O par adjacente referente à seção "como vai", por outro lado, não está caracterizado por uma correspondência prosódica (Fig. 16). A não correspondência prosódica aqui pode ser interpretada como uma indicação de interesse em iniciar um novo tópico conversacional. Efetivamente, um novo tópico conversacional é iniciado logo em seguida:

\section{C39}

0 (toque do telefone)

1 AMALIA: $\operatorname{sim} / /$

2 LUISA: estáAmália //

3 AMALIA: <olá> //

4 LUISA: <olá> // então / viva / como estás //

5 AMALIA: está tudo bem / Luísa < Alice > //

6 LUISA: [NOVO TÓPICO] <eh olha>/vinha saber como é que encontraste o Pedro// 


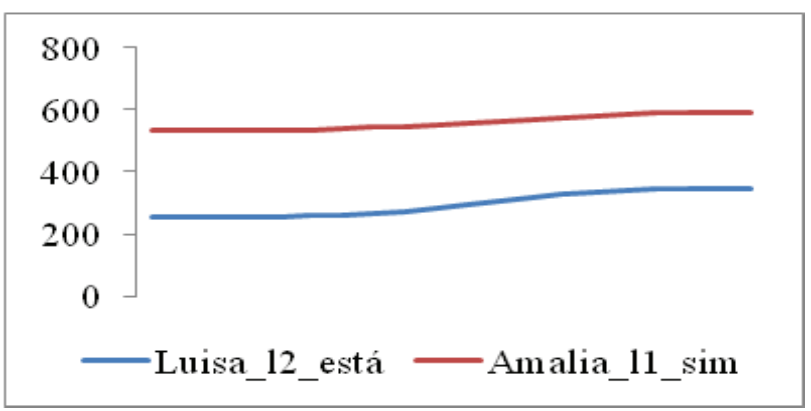

Fig. 14: Contornos de F0 (C39: sim/ está)

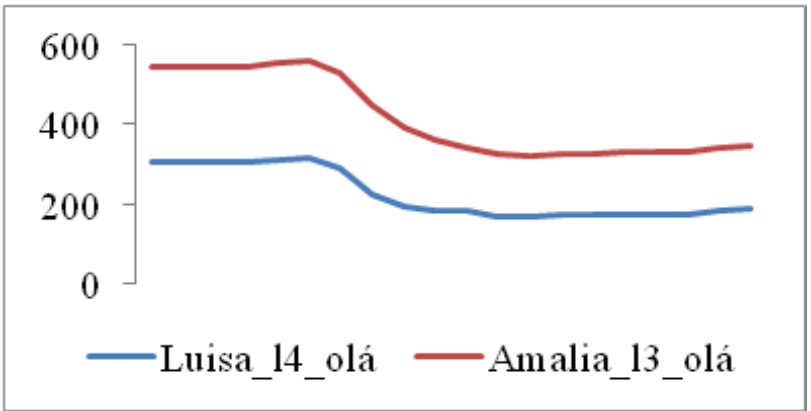

Fig.15: Contornos de F0 (C39: olá / olá)

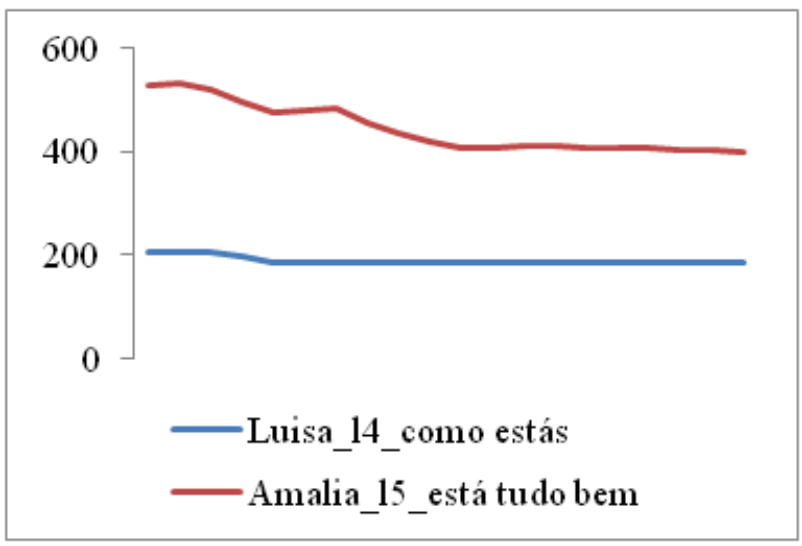

Fig. 16: Contornos de F0 (C39: como estas / esta tudo bem)

Além dos dois exemplos analisados acima, um único outro par adjacente nas sequências de abertura no corpusdeste estudo apresentou não correspondência 
prosódica. Trata-se da seção de troca de cumprimentos no fragmento abaixo:

\section{$\mathrm{C} 12$}

0 (toque do telefone)

1 JOSÉ: estou Carlos //

2 CARLOS: bomdia //

3 JOSÉ: olá bom dia // ainda está com voz de sono //

4 CARLOS: eh levantei-me agora mesmo //

Nesta conversa, JOSÉ é o telefonante. Quando utiliza um contorno entoacional diferente do de seu interlocutor em resposta ao cumprimento "bom dia", como a Fig.17 abaixo explicita, ele evidentemente não quer, neste caso, indicar uma atitude não colaborativa para o desenvolvimento da conversa, algo que seria incoerente, tendo em vista o fato de ter sido ele o autor do telefonema. O que, por outro lado, o uso da não correspondência prosódica parece querer sugerir aqui é um não alinhamento ao tom monocórdio do telefonado, que, para o telefonante, é indicativo de uma "voz de sono". Note que o telefonado confirma a impressão do telefonante, afirmando ter-se levantado naquele instante. A partir deste ponto, encerra-se a sequência de abertura e inicia-se o desenvolvimento do diálogo propriamente.

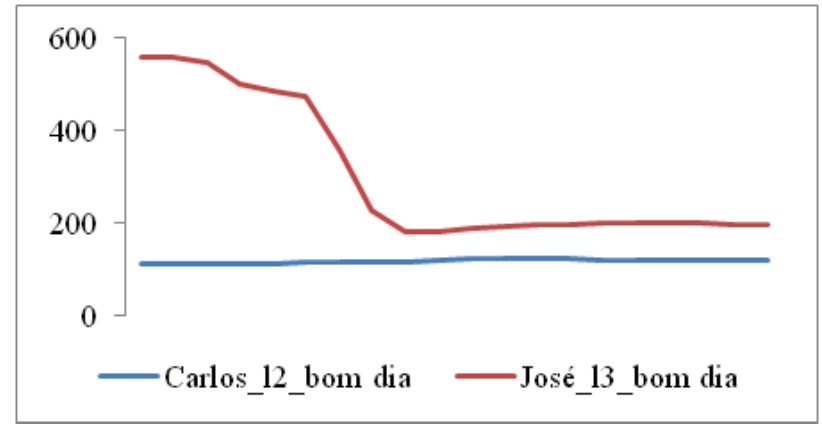

Fig. 17: Contornos de F0 (C12: bom dia / bom dia) 


\section{Conclusão}

Após analisar os pares adjacentes presentes nas sequências de abertura das 48 gravações telefônicas constituintes do corpus final dessa pesquisa, constatamos que apenas 3 não apresentaram correspondência prosódica, indicando ser este um fenômeno produtivo em sequências de abertura de conversas telefônicas no PE.

A correspondência prosódica em geral é utilizada para demonstrar interesse em colaborar para a continuidade conversacional. Todavia, pode cumprir outras funções conversacionais, como, por exemplo, a de adiar a sequência de identificação, na tentativa de reconhecimento da voz do interlocutor, como ilustrado neste estudo. A não correspondência prosódica, por sua vez, é utilizada em situações bastante específicas e, tal como a correspondência prosódica, pode ter múltiplas funções.

Para Gorisch, Wells e Brown (2012), a análise dacorrespondência prosódica situa-se numa área específica da pesquisa linguística que denomina "fonética interacional". Trata-se de um campo ainda muito pouco investigado, mas que merece especial atenção nesta era da tecnologia da informação ubíqua (ARMINEN\& LEINONEN, 2006). Assim, por exemplo, ao demonstrar que a correspondência prosódica é um fenômeno robusto em sequências de abertura de conversas telefônicas no $\mathrm{PE}$, o presente estudo sugere que os modelos dominantes de análise da entoação, baseados exclusivamente no falante, são na melhor das hipóteses apenas parcialmente verdadeiros. Para melhor descrever a produção de padrões entoacionais, será necessário que se leve em conta o contexto em que esses padrões são produzidos, uma vez que podem estar condicionados à fala imediatamente anterior (GORISCH, WELLS \& BROWN, 2012).

É importante considerar que na conversa ao telefone especificamente, os interactantes, por não 
disporem de sinais visuais, lançam mão de maneira mais acentuada de recursos prosódicos para executarem inúmeras ações conversacionais (OLIVEIRA \& FREITAS, 2008). Vale, todavia, salientar que apesar da prosódia ser utilizada na conversação para um grande número de ações simultâneas, raramente essas ações estão associadas exclusivamente à prosódia. De acordo com Reed (2012), outros fenômenos também podem estar associados a certas ações conversacionais, tais como a articulação, o léxico e a gramática.

A análise prosódica não pode, portanto, descartar aspectos globais da conversação, uma vez que a consideração de fenômenos, falantes, ações e pontos específicos não é suficiente para dar conta do uso que se faz da prosódia na conversação. A prosódia representa, assim, um importante indicador de organização sequencial e deve ser abordada como uma estratégia de negociação para a coordenação de ações entre turnos e participantes. 


\section{Referências}

ARMINEN, I.; LEINONEN, M. Mobile phone call openings: tailoring answers to personalized summonses. Discourse Studies, v. 8, n. 3, p. 339-368, 2006.

BROWN, P.; LEVINSON, S. Politeness: some universals in language usage. Cambridge: Cambridge University Press, 1987.

CHAFE, W. L. Discourse, consciousness, and time: the flow and displacement of conscious experience in speaking and writing. Chicago and London: The University of Chicago Press, 1994.

COUPER-KUHLEN, E. The prosody of repetition: on quoting and mimicry. In: COUPER-KUHLEN, E.;SELTING, M., Prosody in conversation: Interactional studies. Cambridge: Cambridge University Press, 1996. p. 366-405.

Prosody and sequence organization in English conversation: The case of new beginnings. In: COUPERKUHLEN,E.;FORD, C. E., Soundpatterns in interaction. Amsterdam: John Benjamins, 2004.p. 335-376.

FREITAS, T. O Português ao Telefone: Sequência de Abertura. In: OLIVEIRA, M., Jr; FREITAS, T. Estudos de Corpora: da teoria à prática. Lisboa: Colibri, 2010. p. 260-288.

GORISCH, J.;WELLS, B.;BROWN, G. J. Pitch contour matching and interactional alignment across turns: An acoustic investigation. Language and Speech, v. 55, n. 1, p. 57-76, 2012.

GRIEVE, A.; SEEBUS, I. G'day or Guten Tag?: A cross-cultural study of Australian and German telephone openings. Journal of Pragmatics, v. 40, n. 7, p. 1323-1343, 2008. 
HUTCHBY, I.; BARNETT, S. Aspects of the sequential organization of mobile phone conversation. Discourse Studies, v. 7, n. 2, p. 147-171, 2005.

LOCAL, J. Continuing and restarting. In: AUER, P.;LUZIO, A. (Eds.), The contextualization of language. Amsterdam: John Benjamins, 1992. p. 273-296.

OLIVEIRA, M., Jr; FREITAS, T. Intonation as a cue to turn management in telephone and face-to-face interactions. In: Proceedings of the 4th International Conference on Speech Prosody, p. 485-488, 2008. Campinas, Brazil.

PARK, Y. Y. Recognition and Identification in Japanese and Korean Telephone Conversation Openings, In: LUKE, K. K.; Pavlidou, T. S. (Eds), Telephone Calls: Unity and Diversity in Conversational Structure across Languages and Cultures. Amsterdam: John Benjamins, 2002. p. 25-47.

REED, B. S. Prosodic Orientation in Spoken Interaction. InLiSt - Interaction and Linguistic Structures, v. 27, 2001. Disponível em: <http://www.uni-potsdam.de/u/inlist/ issues/27/index.htm $>$.

Prosodic Orientation in English Conversation.

Palgrave Macmillan, 2006.

Prosody and alignment: a sequential perspective. Cultural Studies of Science Education, v. 5, n. 4, p. 859-867, 2010.

Beyond the particular: prosody and the coordination of actions. Language and speech, v. 55, n. 1, p. 13-34, 2012.

REITER, R. M.; LUKE, K. Telephone conversation openings across languages, cultures and settings.In: TROSBORG, Anna (Ed.), Pragmatics across languages and cultures. Berlin: De Gruyter Mouton, 2010. p. 103-138. 
SCHEGLOFF, E.A. Sequencing in Conversational Openings. American Anthropologist, v. 70, n. 6, p. 1075-1095, 1968.

SIFIANOU, M. On the telephone again! Telephone conversation openings in Greek. In: LUKE, K. K.;

PAVLIDOU, T. S. (Eds), Telephone Calls: Unity and Diversity in Conversational Structure across Languages and Cultures. Amsterdam: John Benjamins, 2002. p. 49-85.

XU, Y. ProsodyPro, 2012. Disponível em:<http://www.phon. ucl.ac.uk/home/yi/ProsodyPro/>.

[Recebido em 30 de agosto de 2013

e aceito para publicação em 12 de novembro de 2013]

316 LeItURA $=$ MACEIó, N.52, P. 293-316, JUL./DEZ. 2013 